\title{
Statistical study about the influence of particle precipitation on mesosphere summer echoes in polar latitudes during July 2013
}

\author{
Abdur Rauf, Hailong Li', Safi Ullah, Lin Meng, Bin Wang and Maoyan Wang
}

\begin{abstract}
Based on experimental observations with EISCAT VHF radar during the summer period, July 8-12, 2013, the observations of polar mesosphere summer echoes (PMSE) in the absence of particle precipitation indicate that particle precipitation is not a necessary condition for PMSE to exist. But, particle precipitation still affects PMSE when they both occur simultaneously. So in this paper, the relationship between PMSE and particle precipitation both represented by average electron density, occurring simultaneously for time interval of various lengths ( $t \geq 2.56 \mathrm{~min}$ ), is statistically analyzed using the Spearman rank and Pearson linear correlation coefficients. The new method by comparing the average electron density at altitude of $90 \mathrm{~km}$ (proxy of particle precipitation) and PMSE region at altitude of 80-90 km (proxy of PMSE) may compare the two phenomena directly and give some relationship between them. The percentage of events having positive values is dominant, which shows that the electron density variations due to the ionization produced by energetic particle precipitations might have some relationship with PMSE intensity. Moreover, the small percentage of negative correlation coefficient observed might be caused by the very strong precipitation at that time.
\end{abstract}

Keywords: Ionosphere (particles precipitation), Meteorology and atmospheric dynamics (precipitation), PMSE, EISCAT VHF radar

\section{Introduction}

From 1979 onwards, in the upper mesosphere at altitudes of $80-90 \mathrm{~km}$, extremely strong radar echoes called polar mesosphere summer echoes (PMSE) have been observed at polar latitudes (Ecklund and Balsley 1981). PMSE occurs with $80-90 \%$ probability during the main part of the observation period, June until the middle of August (Bremer et al. 2006). Radar echoes require irregularities in electron density at scale half of the radar wavelength (e.g., Bragg scale $\sim 3 \mathrm{~m}$ at $50 \mathrm{MHz}$ ). The existence of charged aerosols is required to maintain this irregularity. Charged aerosols are mainly small ice particles formed because of the low mesospheric summer temperature at polar latitude. The noctilucent clouds (NLC) and PMSE dust particles also contain meteoric material of both

*Correspondence: Hailong703@163.com

School of Electronic Science and Engineering, University of Electronic Science and Technology of China, Chengdu, China the atomic and molecular states injected into the upper mesosphere by ablation of micrometeoroids (Hervig et al. 2001; Plane 2004; Lübken and Höffner 2004; She et al. 2006). Moreover, the large numbers of meteoric smoke particles (MSPs) are the probable constituents of dust particles (Hervig et al. 2012; Havnes et al. 2014). The atmospheric chemistry is affected by the dust/ice particles (Plane et al. 2015). The dust charges are particularly important parameter because they affect ice condensation (Megner and Gumbel 2009) and chemical processes (Baumann et al. 2015). These ice particles are responsible for reducing the electron diffusivity as proposed by Kelley et al. (1987), which will in turn inhibits the fast destruction of the electron's density irregularities required for radar backscattering. The comprehensive description about the detailed physical background of PMSE can be found in (Kelley et al. 1987; Cho and Röttger 1997), and more recently in Rapp and Lübken (2004). 
Ionization provides free electrons necessary for the creation of radar echoes. High-energy particle precipitation can be used as the controlling agent for ionization in the polar mesosphere. The increase in signal-to-noise ratio near midnight in relation to the onset of the particle precipitations, in some case studies, indicates that the ionization produced by particle precipitation may have a role in PMSE creation. Varney et al. (2009) found that most of the PMSE observations by Poker Flat Incoherent Scatter Radar (PFISR) in 2007 during night time were accompanied by the enhanced E-region ionization produced by energetic particle precipitation. The previous lidar observations of mesospheric ice clouds during nighttime in the absence of PMSE have been explained in exactly the same way (von Zahn and Bremer 1999). At polar latitudes, the sun never sets during summer, i.e., solar illumination may vary, but is never zero. This is especially true at $80-90 \mathrm{~km}$ altitude, so solar ionization is never zero. Based on the above-mentioned observations, energetic particle precipitation seems to enhance PMSE at nighttime when solar ionization is weaker.

The geomagnetic $K$-index and the riometric absorption called as cosmic noise absorption (CNA) can be used as a proxy of particle precipitation. The PMSE and CNA maxima often occurred simultaneously (Morris et al. 2005). The main controlling agent for CNA is the electron density in the D-layer (Friedrich and Torkar 1983; Friedrich et al. 2004). Therefore, CNA and geomagnetic activity are well correlated.

To date, several studies, often investigating single event or small data sets, (e.g., Rishbeth et al. 1988; Röttger et al. 1990; Bremer et al. 1995; Rapp et al. 2002; Barabash et al. 2004) have been conducted with mesospheric VHF radar echoes concerning geomagnetic activity. Czechowsky et al. (1989) studied the relationship between absorption and 30-min mean average values of PMSE signalto-noise ratio (SNR) during a period of $50 \mathrm{~h}$ in June 1984 and found a weak positive correlation between the two phenomena. Klostermeyer (1999) used the PMSE observations of ALOMAR SOUSY radar having operating frequency of $53.5 \mathrm{MHz}$ during the periods of low solar activity. He used the two-ion ice particle model and analyzed the daily variation of radar reflectivity and the square of absorption. Klostermeyer (1999) reported a strong correlation for morning and evening events. Based on the model assumption that the condition of electron concentration less than the ice particle concentration is satisfied only during low ionization conditions, it was noted that the strong correlation might not be valid during the strong absorption events. Bremer et al. (2000) used the observations of ALOMAR SOUSY radar near Andenes during the periods of low solar activity. Bremer et al. (2000) detected a positive correlation between
PMSE and geomagnetic activity using a data averages during June and July in the years 1994-1997. Bremer et al. (2001) used the PMSE observations at Andenes with ALWIN radar during 1999 and ALOMAR SOUSY radar during 1994-1997 and analyzed the influence of geomagnetic activity and riometer absorption on PMSE intensity. Bremer et al. (2001) found that PMSE are positively correlated with both the geomagnetic activity and riometer absorption. These correlations have their maximum values near midnight and minimum values during afternoon. Barabash et al. (2002) detected PMSE by using $52 \mathrm{MHz}$ Esrange VHF MST Radar (ESRAD). They analyzed the relationship between linear PMSE intensity and the mean diurnal variation of the square of absorption. Barabash et al. (2002) found a strong correlation between the two phenomena. However, the significant correlation for their day-to-day variations is observed only during the late evening hours. Bremer et al. (2006) estimated the correlation between geomagnetic indices and the monthly mean value of PMSE intensity. They found a significantly positive correlation between PMSE and precipitating particle fluxes (geomagnetic indices used as a proxy). Zeller and Bremer (2009) used the observations of ALWIN and OSWIN radars both having operating frequencies of $53.5 \mathrm{MHz}$. They analyzed the daily means of geomagnetic activities and VHF radar echoes and observed an enhancement of PMSE during the maximum of geomagnetic activity. Smirnova et al. (2010) studied the day-to-day and year-to-year variation of PMSE reflectivity $\eta$ and the local geomagnetic $K$-index as averaged over $24 \mathrm{~h}$ and for every 3-h interval. They used the PMSE observations taken from ESRAD $52 \mathrm{MHz}$ and found that PMSE has correlation with geomagnetic activity. The relationship of the PMSE occurrence rates at $224 \mathrm{MHz}$ with $A_{\mathrm{P}}$ index was analyzed by $\mathrm{Li}$ and Rapp (2011). They found that PMSE shows a positive correlation with $A_{\mathrm{P}}$ index. The correlation of PMSE at $224 \mathrm{MHz}$ to the ionization level, however, is less significant than that at 53.5 MHz. Antonsen and Havnes (2015) found a weak positive correlation between PMSE strength and rapid changes in electron density for moderately strong echoes.

From the literature, we know that the relationship between PMSE observed with MST radars at about $50 \mathrm{MHz}$ and particle precipitation was mainly investigated by using magnetic disturbance indices and CNA as a proxy of high-energy particle precipitation (Bremer et al. 1995, 2000, 2001, 2006; Barabash et al. 2002; Zeller and Bremer 2009; Smirnova et al. 2010). These parameters used as a proxy of particle precipitation give information about the mean background ionization in the D-region of ionosphere. However, PMSE show different characteristics at different frequencies, so in this article 
the average electron density at altitude of $90 \mathrm{~km}$ is used as a proxy of particle precipitation to study its relation to PMSE observed at $224 \mathrm{MHz}$. This height is very close to the PMSE region, so a direct relationship may be found between particle precipitation and PMSE.

In this article, the relationship between the two phenomena is analyzed based on the observations of PMSE in the presence of particle precipitation. Correlation coefficients are computed during simultaneous occurrence of the two phenomena for time intervals of various lengths $(t \geq 2.56 \mathrm{~min})$. Moreover, the correlation coefficients are computed by combining all the data points having simultaneously occurring PMSE and particle precipitation in each hour, each day, and finally for all the 5 -day campaign. The advantage of this study is that it will give us a deep insight into the relationship between the two phenomena by finding the correlation for short and longer time intervals. The goal of this article is to discuss the internal relationship between PMSE and energetic particle precipitation.

\section{Radar and experiment description}

The investigation of PMSE was carried out with the EISCAT VHF radar located near Troms $ø$, Norway $\left(69^{\circ} 35^{\prime} \mathrm{N}\right.$, $19^{\circ} 14^{\prime} \mathrm{E}$ ). This radar operates at frequency of $224 \mathrm{MHz}$ with a maximum duty cycle and peak power of $12.5 \%$ and 1.6 MW, respectively. The geomagnetic inclination and invariant latitude are $77^{\circ} 30^{\prime} \mathrm{N}$ and $66^{\circ} 12^{\prime} \mathrm{N}$, respectively. It has a pulse length of $1 \mu$ s to $2 \mathrm{~ms}$ with frequency and phase modulation capability. The antenna used for transmission and reception is a parabolic cylinder consisting of 4 quarters, constituting a total aperture of $120 \mathrm{~m} \times 40 \mathrm{~m}$. During the PMSE measurements used here, EISCAT VHF radar ran an operating mode "manda CP-6." CP-6 is designed for low-altitude studies, providing spectral measurements at mesospheric heights. The main technical details of the experiment mode are summarized in Table 1.

\section{Data analysis}

The radar data of summer period, July $8-12,2013$, have been used because the seasonal variation of PMSE during this month is small in contrast to the continuous decrease in August and the steep increase during May (Hoffmann et al. 1999). The EISCAT VHF radar was operated for approximately $111 \mathrm{~h}$ during the 5-day campaign. The details of all the 5-day campaign are given in Table 2.

To find the correlation between particle precipitation and PMSE intensity, a measurement of both must be defined. Because the PMSE occur in thin layers having thickness up to few kilometers, so the PMSE region in the altitude range of $80-90 \mathrm{~km}$ was first detected by using the threshold of electron density $\left(N_{\mathrm{e}} \geq 4.6 \times 10^{11} \mathrm{~m}^{-3}\right)$
Table 1 Technical details of the experiment mode

\begin{tabular}{ll}
\hline Experiment modes & Manda CP-6 \\
\hline Version & 4.0 \\
Raw data available & Yes \\
Plasma line & - \\
Integration time & $4.8 \mathrm{~s}$ \\
Height range & $20-195 \mathrm{~km}$ \\
Code & Alternating, 61 bit, 128 subcycles \\
Baud length & $2.4 \mu \mathrm{s}$ \\
Sampling rate & $1.2 \mu \mathrm{s}$ \\
Subcycle length & $1.5 \mathrm{~ms}$ \\
Duty cycle & 0.098 \\
\hline
\end{tabular}

and then calculated the average of data points satisfying PMSE threshold. The presence of PMSE radar echoes were defined as the average electron density $\left(N_{\mathrm{e}} \geq 4.6 \times 10^{11} \mathrm{~m}^{-3}\right)$. The electron density value used for PMSE is within the threshold range used by Hocking and Röttger (1997). Since the range of electron density in the E-region $(90-150 \mathrm{~km})$ of ionosphere is about $10^{10}-10^{11} \mathrm{~m}^{-3}$, so the particle precipitations reaching at altitude of $90 \mathrm{~km}$ were detected using electron density $\left(N_{\mathrm{e}} \geq 10^{11} \mathrm{~m}^{-3}\right)$ and then calculated the average of data points satisfying the threshold defined for particle precipitation. The average electron density $\left(N_{\mathrm{e}} \geq 10^{11} \mathrm{~m}^{-3}\right)$ at altitude of $90 \mathrm{~km}$ was used as a proxy of high-energy particle precipitation.

The correlation coefficients have been calculated only for simultaneously occurring particle precipitation and PMSE intensity for time interval $(t \geq 2.56 \mathrm{~min})$. Because the integration time of manda CP- 6 is $4.8 \mathrm{~s}$, so according to the condition ( $t \geq 2.56 \mathrm{~min}$ ), the PMSE and particle precipitations are needed to be simultaneous for $\geq 32$ data points. As the PMSE are not continuous in time, so in any time interval, if there were less than 8 data points which do not satisfy the PMSE threshold defined in this study, then those data points were replaced by the average of $N_{\mathrm{e}}$ between 80 and $90 \mathrm{~km}$ without using any threshold. Similarly, if there were less than 8 data points which do not satisfy the threshold defined for particle precipitation in this study, then those data points were replaced by the average of $N_{\mathrm{e}}$ at $90 \mathrm{~km}$ without using any threshold. This is to keep the original electron density values at these corresponding times and does not affect the correlation. However, if the discontinuity in the simultaneous occurrence of the two phenomena in any event was for $\geq 8$ data points, then those events were not considered in this study. The minimum numbers of 32 data points were used because the correlation coefficients computed for data points very small in numbers may be high but may not be statistically significant. 
Table 2 Details about PMSE and particle precipitation during 5-day campaign

\begin{tabular}{|c|c|c|c|c|c|c|}
\hline Days in July & PMSE (\%) & Precipitation (\%) & $\begin{array}{l}\text { Simultaneous PMSE } \\
\text { and precipitation (\%) }\end{array}$ & $\begin{array}{l}\text { No PMSE } \\
\text { and no precipitation } \\
(\%)\end{array}$ & $\begin{array}{l}\text { PMSE } \\
\text { with no precipitation } \\
(\%)\end{array}$ & $\begin{array}{l}\text { Precipitation } \\
\text { with no PMSE (\%) }\end{array}$ \\
\hline 8 & 30.78 & 3.52 & 2.62 & 68.31 & 28.17 & 0.90 \\
\hline 9 & 26.09 & 1.62 & 0.70 & 73.00 & 25.39 & 0.91 \\
\hline 10 & 73.77 & 34.95 & 32.60 & 23.88 & 41.17 & 2.35 \\
\hline 11 & 62.91 & 36.91 & 27.24 & 27.42 & 35.67 & 9.67 \\
\hline 12 & 17.39 & 22.81 & 3.50 & 63.31 & 13.89 & 19.30 \\
\hline $08-12$ & 43.71 & 17.86 & 13.06 & 51.49 & 30.65 & 4.80 \\
\hline
\end{tabular}

The data used in the article are shown in Fig. 1. It is clear from Fig. 1 that the altitude ranging from 80 to $130 \mathrm{~km}$ is divided into two panels (a) and (b), representing the particle precipitation reaching to altitude of $90 \mathrm{~km}$ and PMSE region, respectively. The purpose of dividing the figure into two panels is that the electron density representing the particle precipitation is greater than that in the PMSE region, so if we plot the electron density as a single figure, then for the color bar limit of [9 14], the electron density representing particle precipitation will be clearly visible, but the electron density in PMSE region will not be clear. However, for the color bar limit of [9 12], the electron density in PMSE region will be clearly visible; however, the electron density representing particle precipitation will be badly saturated.

The main focus of this study is the correlation between PMSE and particle precipitation during their simultaneous occurrence. From Fig. 1, it is clear that particle precipitation and PMSE do not continuously appear simultaneously. The percentage of simultaneous occurrence of PMSE and particle precipitation on July $08-12$, given in Table 2, is 2.62, 0.70, 32.60, 27.24, and 3.50\%, respectively. Based on the percentage of simultaneous occurrence of the two phenomena, more events have been observed on July 10 and 11 . Because the percentage of simultaneous occurrence of the two phenomena on July 09 is very small, that is, for time interval of less than $2.56 \mathrm{~min}$, therefore, no correlation coefficient is computed on July 09 .

\section{Methods}

In this statistical study, the relationship between the variation in PMSE intensity and high-energy particle precipitation has been estimated using two methods: Pearson linear correlation and the Spearman rank correlation (Wilks 1995). Pearson linear correlation coefficient is the ratio of the sample covariance of two variables to the product of their standard deviations, given by Eq. (1):

$$
r_{x y}=\frac{\operatorname{cov}(X, Y)}{s_{x} s_{y}}
$$

There are two limitations of using this correlation: it is neither robust nor resistant. It is not robust because it only recognizes the linear relationship between the two variables and may not be able to recognize even strong nonlinear relationships. This correlation is not resistant because it can be affected by outliers. Indeed, a single outlier can result in a highly inaccurate summary of data. An alternate to the Pearson linear correlation is Spearman rank correlation. This robust and resistant correlation can be calculated by using ranks of the data. This correlation recognizes the strength of the monotonic relationships and is not affected by outliers.

The statistical significance of all the correlation coefficients has been tested by computing the $F$ statistics ( $p$ values). It is used to determine whether the null hypothesis (a general statement that there is no relationship between the two measured phenomena) should be rejected or retained. If a $p$ value is less than the significance (alpha) level, the hypothesis test is statistically significant, and the null hypothesis should be rejected. Thus, $p$ value is a tool for deciding whether to reject or accept the null hypothesis.

There are different confidence levels (90, 95, and 99\%) for testing the statistical significance of correlation coefficient. These confidence levels depend on the significance (alpha) level. The significance levels for the above-mentioned confidence levels are $0.1,0.05$, and 0.01 , respectively. We have retained only those Pearson linear and Spearman rank correlation coefficients which are statistically significant with $95 \%$ confidence level, that is, for which the $p$ values are less than the commonly used level of significance $(\alpha=0.05)$.

We have also calculated the coefficient of determination $\left(r^{2}\right)$, which is equal to the square of correlation coefficient. It is more informative when interpreting the magnitude of the relation between two variables, regardless of directionality. It gives us the proportion of variance in the dependent variable predicted from the independent variables. Therefore, this is useful in explaining the percentage of variance in PMSE intensity due to high-energy particle precipitation. 


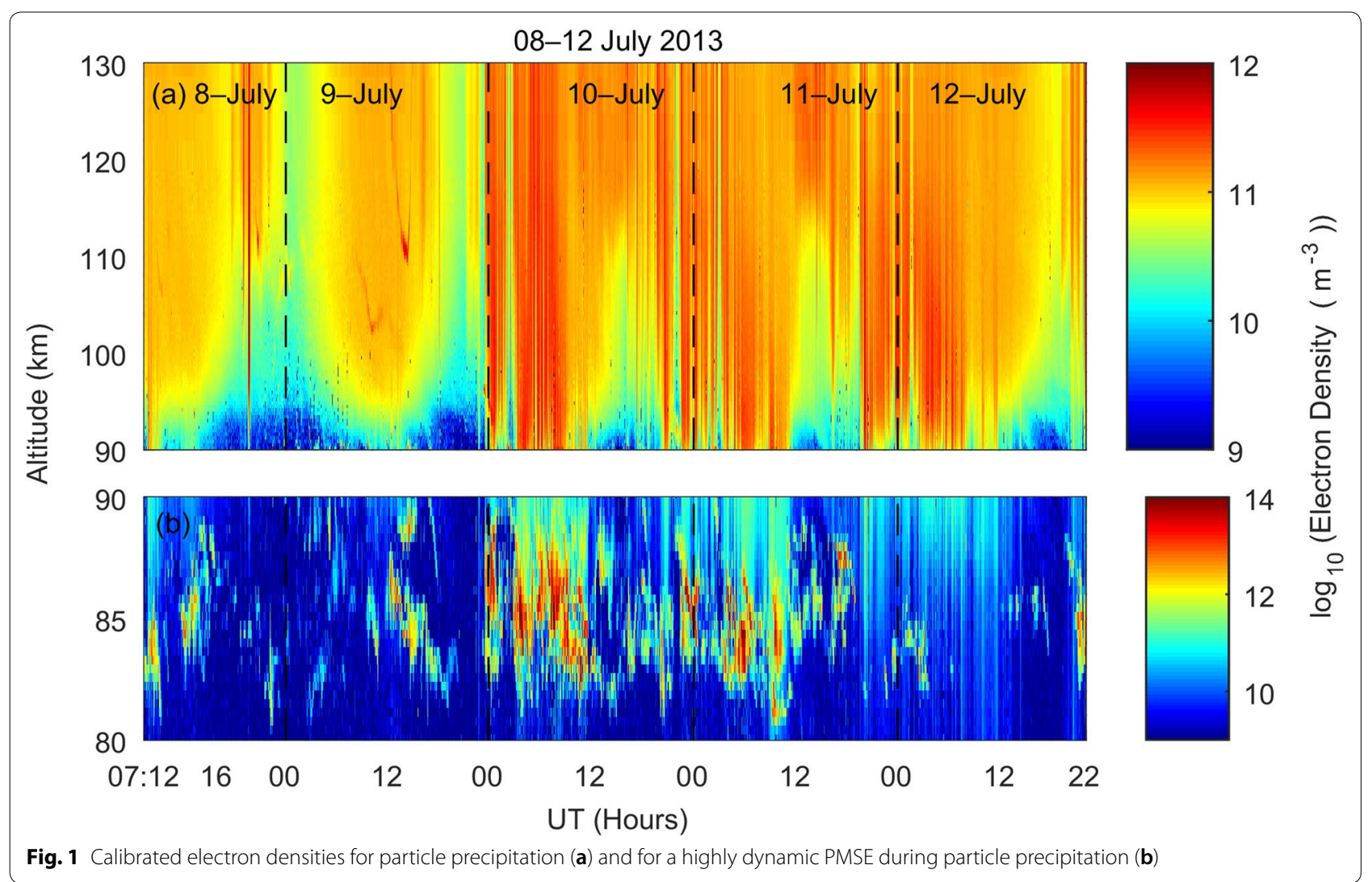

The strength of the correlation using the guide that Evans (1996) suggests for the absolute value of correlation coefficient can be described as: $[ \pm .00 \pm .19],[ \pm .20$ \pm .39 ], [ $\pm .40 \pm .59],[ \pm .60 \pm .79]$, and $[ \pm .80 \pm 1.0]$, which represents the very weak, weak, moderate, strong, and very strong correlations, respectively. The percentages of the coefficient of determination corresponding to the different ranges of correlation coefficients are as follows: [0 3.61], [4 15.21], [16 34.81], [36 62.41], and [64 $100 \%]$.

\section{Results}

The effect of energetic particle precipitation fluxes on PMSE will be discussed by using the observations of EISCAT VHF radar during the summer period July 08-12, 2013. The investigation of the influence of highenergy particle precipitation on PMSE intensity has been performed using the Pearson linear and Spearman rank correlation coefficients. The correlation coefficients are computed for time intervals of various lengths $(t \geq 2.56 \mathrm{~min})$. Moreover, the correlation coefficients are computed by combining all the data points having simultaneous occurrence of PMSE and particle precipitation in each hour, each day, and finally all the 5-day campaign.
The conclusion is based on the more robust Spearman rank correlation coefficients.

\section{Correlation coefficients for time intervals of various lengths ( $t \geq 2.56 \mathrm{~min}$ )}

Figure 2 shows the correlation coefficients computed for time intervals of various lengths $(t \geq 2.56 \mathrm{~min})$. The length of an event depends on the simultaneous occurrence of PMSE and particle precipitation. The length of the lines represents the time interval for which PMSE and particle precipitation occur simultaneously. Figure 2 shows that there are, respectively, 36 and 35 events in all the 5-day campaign having statistically significant Pearson linear and Spearman rank correlation coefficients. It is also clear from this figure that there are, respectively, nine and eight events for which the Pearson linear and Spearman rank correlation coefficients have negative values, whereas 27 events have positive values for both Pearson linear and Spearman rank correlation coefficients.

Figure 3 shows the percentage of occurrence of different ranges of Pearson linear and Spearman rank correlation coefficients computed for different events in all the 5-day campaign. 


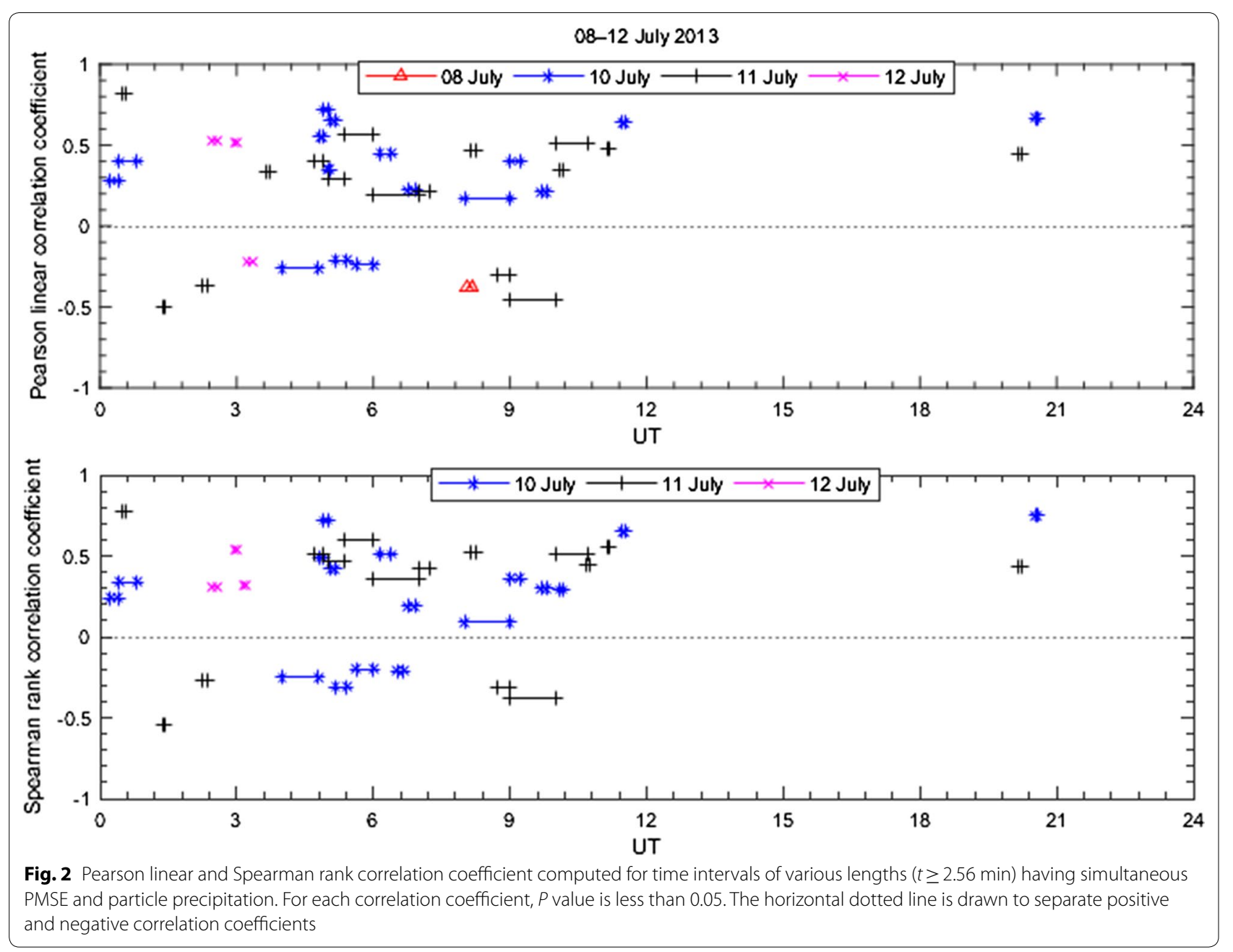

Figure 3a shows that the percentages of occurrence of weak and moderate negative Pearson linear correlation coefficient are 19.44 and $5.56 \%$, respectively. On the other hand, the percentages of occurrence of very strong, strong, moderate, weak, and very weak positive Pearson linear correlation coefficient are 2.78, 11.11, 33.33, 22.22 , and $5.56 \%$, respectively. This means that there are $75 \%$ events having positive values, whereas $25 \%$ of the events have negative values of Pearson linear correlation coefficients.

Figure $3 \mathrm{~b}$ shows that the percentages of occurrence of weak and moderate negative Spearman rank correlation coefficient are 20 and $2.86 \%$, respectively. The percentages of occurrence of strong, moderate, weak, and very weak positive Spearman rank correlation coefficient are $14.29,34.29,22.86$, and $5.70 \%$, respectively. This means that there are $77.14 \%$ events having positive values, whereas $22.86 \%$ of the events have negative values of Spearman rank correlation coefficients.

\section{Correlation coefficients for all the combined data points having simultaneous occurrence of PMSE and particle precipitation in each hour}

The correlation coefficients shown in Fig. 4 were computed by combining all the data points in each hour having simultaneous occurrence of PMSE and particle precipitation for time interval $(t \geq 2.56 \mathrm{~min})$. Figure 4 shows that there are 23 events in all the 5-day campaign, having statistically significant Pearson linear and Spearman rank correlation coefficients. It is also clear from this figure that there are six events for which both the Pearson linear and Spearman rank correlation coefficients have negative values, whereas there are 17 events having positive values for both Pearson linear and Spearman rank correlation coefficients.

Figure 5 shows the percentage of occurrence of different ranges of Pearson linear and Spearman rank correlation coefficients computed by combining all the data points having simultaneous occurrence of PMSE and particle precipitation in each hour during a 5-day campaign. 

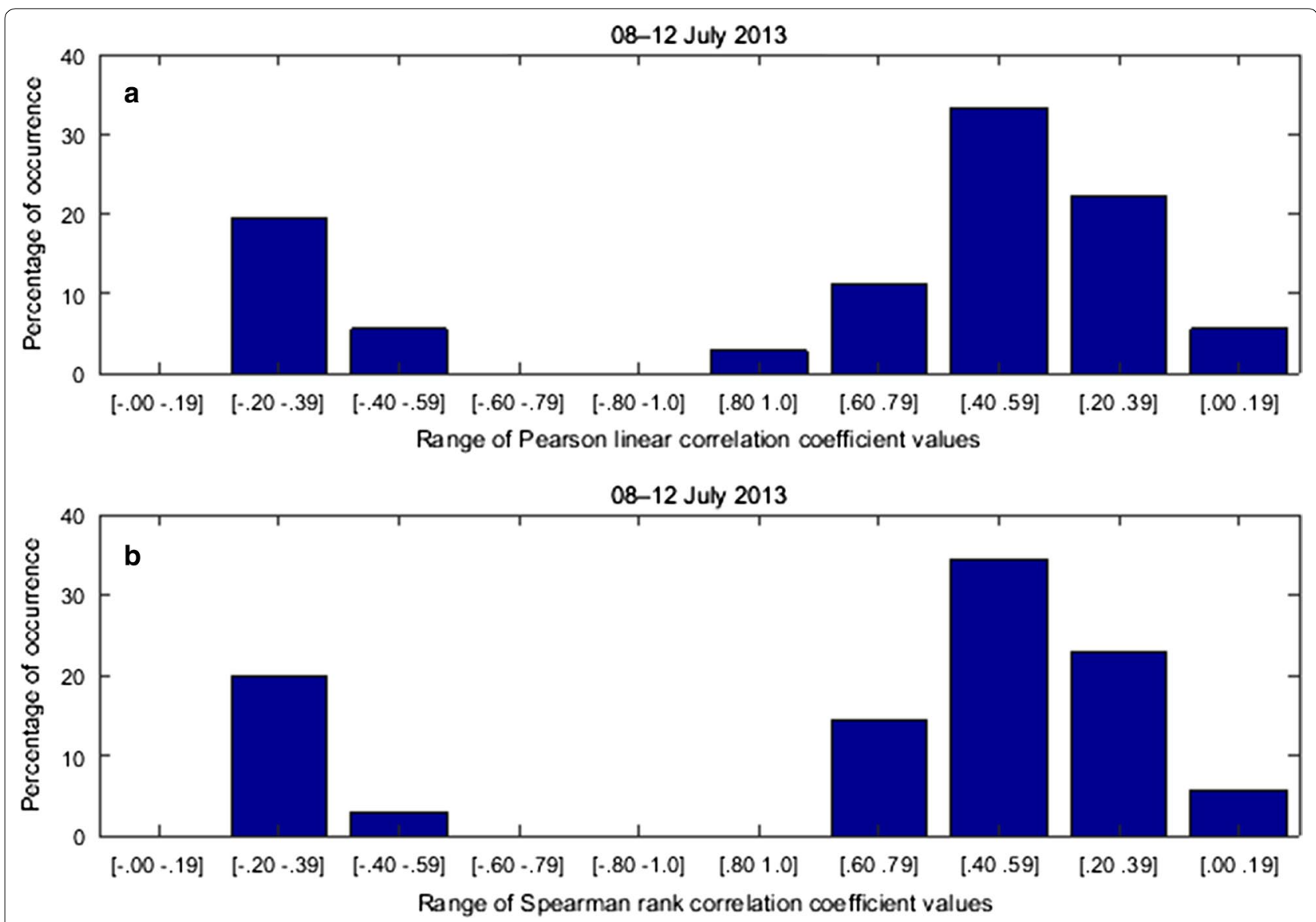

Fig. 3 Percentage of occurrence of different ranges of Pearson linear correlation coefficient (a) and Spearman rank correlation coefficient (b) for all events in 5-day campaign

Figure 5a shows that the percentages of occurrence of very weak, weak, and moderate negative Pearson linear correlation coefficient are $17.40,4.35$, and $4.35 \%$, respectively. The percentages of occurrence of strong, moderate, weak, and very weak positive Pearson linear correlation coefficient are $8.69,8.69,13.04$, and $43.48 \%$, respectively. This means that there are about $73.90 \%$ events having positive values, whereas about $26.10 \%$ events have negative values of Pearson linear correlation coefficients.

Figure $5 \mathrm{~b}$ shows that the percentages of occurrence of very weak, weak, and moderate negative Spearman rank correlation coefficients are 13.08, 8.69, and 4.35\%, respectively. The percentages of occurrence of strong, moderate, weak, and very weak positive Spearman rank correlation coefficients are 4.35, 17.39, 39.13, and 13.01\%, respectively. This means that there are $73.88 \%$ events having positive values, whereas about $26.12 \%$ events have negative values of Spearman rank correlation coefficients.
Correlation coefficients for all the combined data points having simultaneous occurrence of PMSE and particle precipitation in each day

To further investigate the correlation between PMSE and particle precipitation, we have combined all the data points of each day having simultaneous occurrence of the two phenomena. Table 3 shows the correlation coefficients computed by combining all the data points having simultaneous occurrence PMSE and particle precipitation for time interval ( $t \geq 2.56 \mathrm{~min}$ ) in each day.

The $P$ value is used to decide whether to reject or accept the null hypothesis (a general statement that there is no relationship between the two measured phenomena). The $P$ value less than the significance level $(\alpha=0.05)$ for any correlation coefficients can reject the null hypothesis, and the correlation coefficients are considered statistically significant with $95 \%$ confidence level. From Table 3, it is clear that all the correlations except from the Pearson linear correlation coefficient on July 12 are statistically significant. 


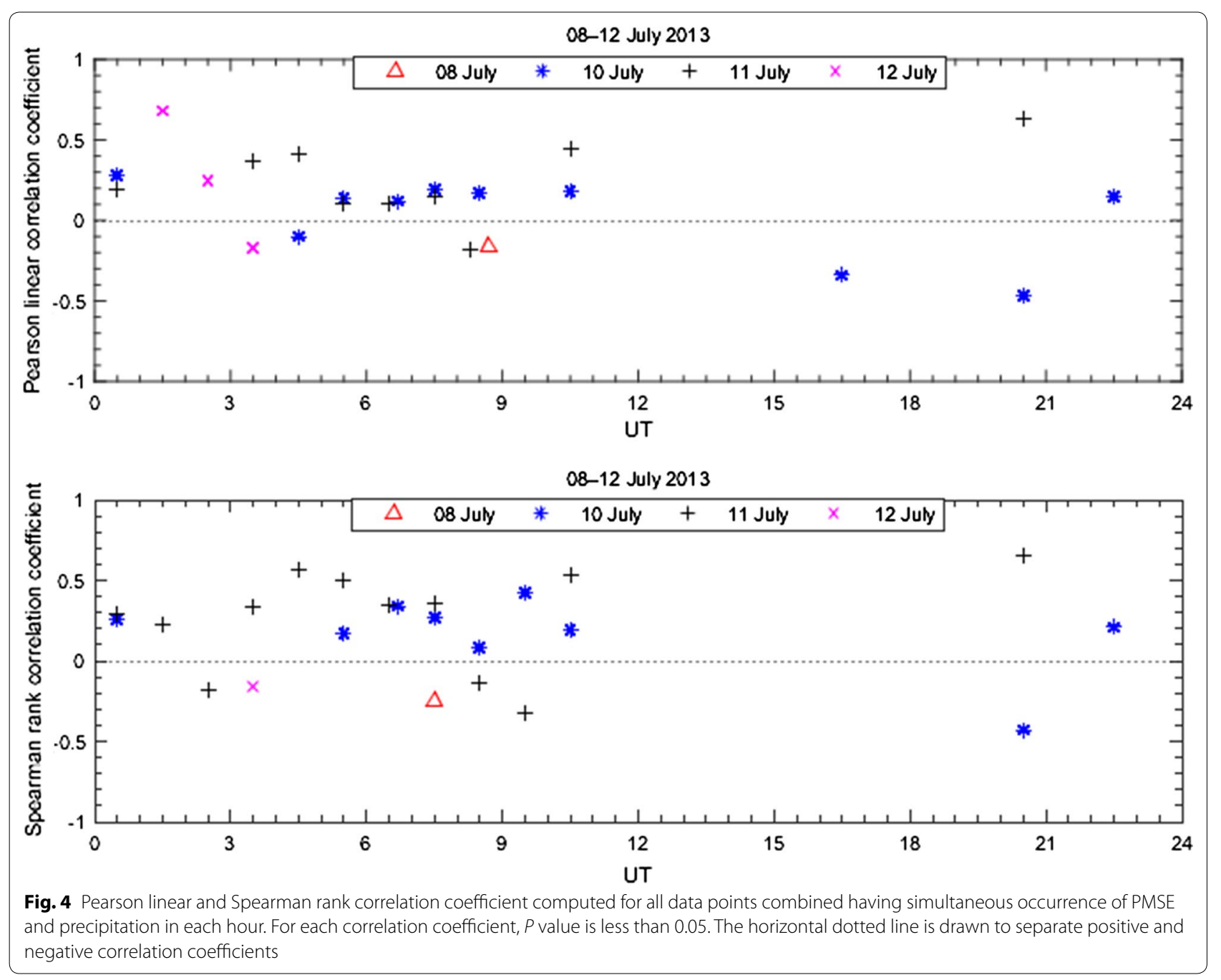

It can be seen from Table 3 that no correlation coefficient is computed on July 09 because the percentage of simultaneous occurrence of the two phenomena on this day, shown in Table 2, is only $0.70 \%$, which is for a time interval less than $2.56 \mathrm{~min}$. It is also clear from Table 3 that the Pearson linear correlation coefficient has positive values on July 10 and 11, whereas a negative value on July 08 . The Pearson linear correlation coefficient on July 12 is not statistically significant, because it has $P$ value greater than 0.05 . The Spearman rank correlation coefficient also has positive values on both July 10 and 11 , whereas a negative value on July 08 and 12 . This apparently means that $67 \%$ of Pearson linear correlation and $50 \%$ of Spearman rank correlation coefficients have positive values, whereas $33 \%$ of Pearson linear correlation and $50 \%$ of Spearman rank correlation coefficient have negative values. However, from Table 2, we know that percentage of data points having simultaneous occurrence of PMSE and particle precipitation on July 08 and 12 is very small as compared with that on July 10 and 11 . The total number of data points having simultaneous occurrence of PMSE and particle precipitations on July 08 and 12 is 420 and 573 , respectively, while on July 10 and 11 , it is 5540 and 4704, respectively. Observation time of each day is not the same because the VHF radar did not run continuously and there had some breaks for short times on July 08,09 , and 11 . If the number of data points on July 08 and 12 was similar with that on July 10 and 11 , then the correlation coefficients on July 08 and 12 may become negligible as compared to that on July 10 and 11 . Therefore, we could say that the events having positive values are also dominant in case of correlation coefficient computed for all the combined data points having simultaneous occurrence of PMSE and particle precipitation in each day. 


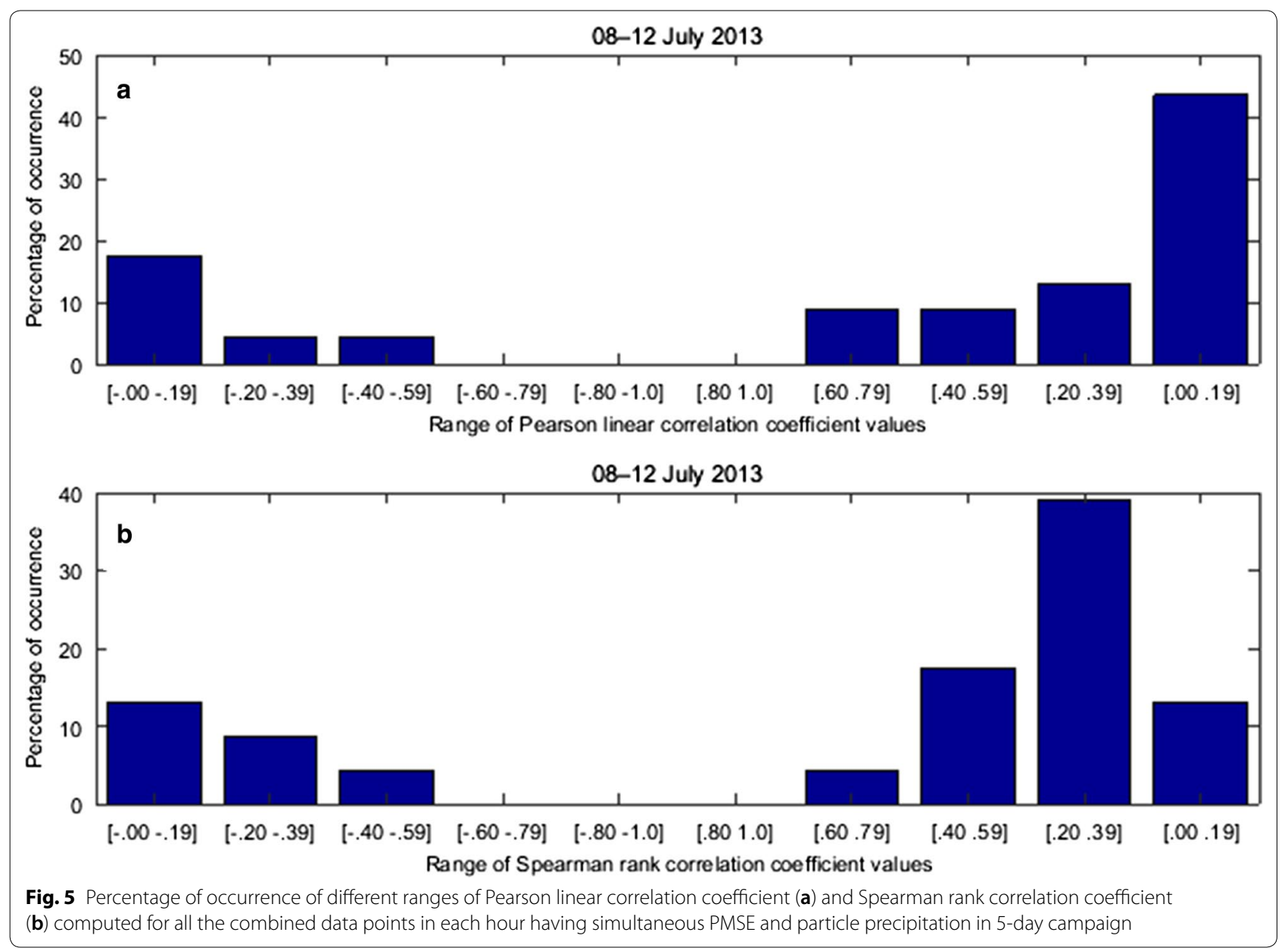

Table 3 Correlation coefficients computed for all the combined data points having simultaneous occurrence of PMSE and particle precipitation in each day

\begin{tabular}{lll}
\hline Days in July & Pearson linear correlation coefficient & Spearman rank correlation coefficient \\
\hline 8 & -0.24 & -0.29 \\
& $(P=0.00)$ & $(P=0.00)$ \\
10 & 0.05 & 0.07 \\
& $(P=0.00)$ & $(P=0.00)$ \\
11 & 0.24 & 0.34 \\
& $(P=0.00)$ & $(P=0.00)$ \\
12 & -0.03 & -0.17 \\
& $(P=0.44)$ & $(P=0.00)$ \\
\hline
\end{tabular}

Correlation coefficients for all the combined data points having simultaneous occurrence of PMSE and particle precipitation in all 5 days

Finally, we computed the Pearson linear and Spearman rank correlation coefficient by combining all the data points in 5 days, having simultaneous occurrence of
PMSE and particle precipitation. It is clear from Fig. 6 that both the Pearson linear and Spearman rank correlation coefficients have positive values. Although the correlation coefficients are weak, they are statistically significant. Therefore, based on the more robust Spearman rank correlation coefficient computed for all the 5 days, 


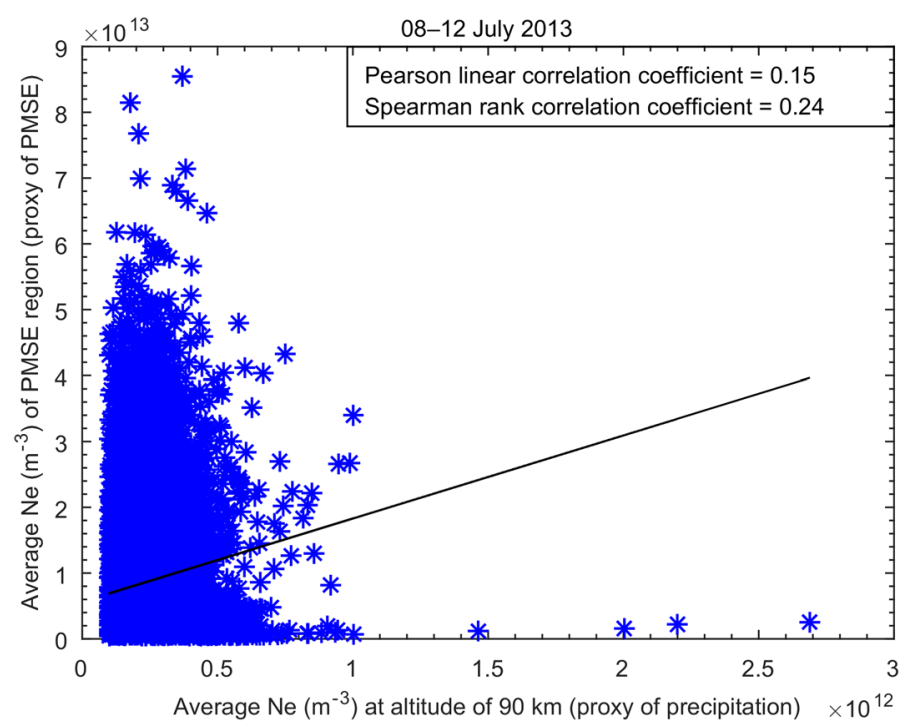

Fig. 6 Scatter plot of average $N_{e}$ at altitude of $90 \mathrm{~km}$ (proxy of precipitation) versus average $N_{e}$ in PMSE region (proxy of PMSE) for all data points combined having simultaneous occurrence of PMSE and particle precipitation during 08-12 July

we could say that particle precipitation might be one possible contributing component for PMSE creation.

\section{Discussion}

In this section, we will discuss the possible reasons for both the positive and negative correlation coefficients observed in this study.

\section{Positive correlation between PMSE and particle precipitation}

If electrons are necessary for PMSE creation, then the probability of PMSE observation during nighttime without some extra source of ionization may become small when the normal D-region electron has recombined. Most of the nighttime PMSE observed by Poker Flat Incoherent Scatter Radar (PFISR) in 2007 were accompanied by the enhanced E-region ionization produced by energetic particle precipitation (Varney et al. 2009). The observation made by National Institute of Information and Communications Technology (NICT) Rayleigh lidar at Poker Flat on August 12, 2009, detected a mesospheric ice cloud between 01:07 and 02:03 Alaska Standard Time, but no signals were detected whatsoever in any look direction, including the common volume vertical beam. The occurrence of this event takes place in darkness without energetic particle precipitation. Hence, the lack of free electrons could be considered as a trivial explanation for the absence of PMSE. The previous lidar observations of mesospheric ice clouds during nighttime in the absence of PMSE have been explained in exactly the same way (von Zahn and Bremer 1999). Based on the above observations, energetic particle precipitation seems to enhance PMSE at nighttime when solar ionization is weaker.

It is well known from the particle events in the polar cap and auroral zone that there is an increase in electron density due to enhanced particle precipitation. Besides, there is a probability of temperature changes in mesoand lower thermosphere. However, it is not quite clear if the temperature always increases as expected from some observations (von Savigny et al. 2007) and model calculations (Roble et al. 1987; Barabash et al. 2004). Jackman et al. (2007) found that the temperature is decreasing in most cases of the investigated events. Singer et al. (2008) reported that the observations made with meteor radars in polar (Andenes, $69^{\circ} \mathrm{N}$ ) and middle (Juliusruh, $54^{\circ} \mathrm{N}$ ) latitudes also gave strong indications for such temperature decreases, which may have a dynamic cause. On the other hand, if temperature was increased because of particle precipitation, then the photo-dissociation of water vapor may destroy PMSE by compensating the increasing electron density. Bremer et al. (2006) observed an unusual low PMSE occurrence rate during the year 2002. The mesospheric temperature at polar latitude during this year was about $10 \mathrm{~K}$ higher than other years shown by meteor radar observations at Andenes (Singer et al., 2005).

The correlation coefficients for simultaneously occurring PMSE and particle precipitation shown in Figs. 2, 4 , and Table 3 clearly show that the number of events having positive value is more than those having negative 
values. Moreover, Fig. 6 also shows a positive correlation for large data set having simultaneous occurrence of PMSE and particle precipitation in all 5-day campaign. Based on these observations, it could be reasonable to suggest that particle precipitation responsible for ionization in the ionosphere D-region might be one contributing reason for PMSE observed in this study.

\section{Negative correlation between PMSE and particle precipitation}

The extremely strong events of precipitating energetic particles cause the electron density to increase by several orders of magnitude. Therefore, following the theory of Cho et al. (1992), it was assumed by Rapp et al. (2002) that the PMSE should be weakened when the ratio of aerosols charge to electron number density becomes markedly smaller than one. Bremer et al. (1995) found a negative correlation between PMSE at $224 \mathrm{MHz}$ and geomagnetic activity. Bremer et al. (1995) explained that this negative correlation coefficient can be due to particle precipitation.

Because there will be smaller changes in the background in $1 \mathrm{~h}$, the maximum electron density for different events, having both positive and negative Spearman rank correlation coefficient in $1 \mathrm{~h}$, was compared to investigate the effect of electron density on negative correlation between PMSE and particle precipitation. Table 4 clearly shows that the events having both positive and negative values of Spearman rank correlation coefficients in $1 \mathrm{~h}$ are observed only on July 10 and 11 . On July 08 and 12, there is no event having negative values of Spearman rank correlation coefficient (see second panel of Fig. 2). That is why, there are no events on July 08 and

Table 4 Comparison of maximum $N_{e}\left(\mathrm{~m}^{-3}\right)$ for events in $1 \mathrm{~h}$, having positive and negative Spearman rank correlation coefficient values

\begin{tabular}{|c|c|c|c|}
\hline Days in July & UT (h:min:s) & $\begin{array}{l}\text { Spearman } \\
\text { rank } \\
\text { correlation } \\
\text { coefficient }\end{array}$ & $\begin{array}{l}\text { Maximum } N_{\mathrm{e}} \\
\left(\mathrm{m}^{-3}\right)\end{array}$ \\
\hline \multirow[t]{9}{*}{10} & 04:00:04-04:47:31 & -0.25 & $6.98 \times 10^{11}$ \\
\hline & 04:50:00-04:53:31 & 0.49 & $2.88 \times 10^{11}$ \\
\hline & 04:54:14-04:59:55 & 0.72 & $2.30 \times 10^{11}$ \\
\hline & 05:00:04-05:02:38 & 0.35 & $2.14 \times 10^{11}$ \\
\hline & 05:03:26-05:09:16 & 0.42 & $4.93 \times 10^{11}$ \\
\hline & 05:10:33-05:25:36 & -0.31 & $5.43 \times 10^{11}$ \\
\hline & 05:38:00-05:59:55 & -0.20 & $6.55 \times 10^{11}$ \\
\hline & 06:31:07-06:40:00 & -0.21 & $4.02 \times 10^{11}$ \\
\hline & 06:45:07-06:54:38 & 0.19 & $3.62 \times 10^{11}$ \\
\hline \multirow[t]{2}{*}{11} & 08:09:16-08:15:31 & 0.52 & $1.65 \times 10^{11}$ \\
\hline & 08:42:14-08:59:55 & -0.31 & $3.24 \times 10^{11}$ \\
\hline
\end{tabular}

12 shown in Table 4 . It is shown in Table 4 that during the same hour, maximum electron density for events having negative correlation coefficient has higher values than those having positive correlation coefficient. Therefore, it might be reasonable for negative correlation coefficients observed for different events in $1 \mathrm{~h}$ that the maximum electron density during extremely strong precipitation could cause the weakening of PMSE intensity and hence the negative correlation. However, the background is changing for different hours and days, so for the negative correlation observed for the combined data points having simultaneous PMSE and particle precipitation in each hours and each day shown in Fig. 4 and Table 3, respectively, it could be reasonable to suggest that there might be some other factors causing the PMSE to weaken and hence the negative correlation coefficient.

\section{Summary and conclusion}

In this article, the relation between PMSE and particle precipitation is analyzed during 5 days of observations with EISCAT VHF $224 \mathrm{MHz}$ radar. The observations of PMSE in the absence of particle precipitation indicate that particle precipitation is not a necessary condition for PMSE to exist. However, particle precipitation still affects PMSE when they both occur simultaneously. Here the relationship between precipitating particles reaching to altitude of $90 \mathrm{~km}$ and mesosphere summer echoes in polar latitudes, only during their simultaneous occurrence, is presented. For this investigation, we have compared the average electron density at $90 \mathrm{~km}$ (proxy of precipitation) and average electron density of PMSE region from 80 to $90 \mathrm{~km}$. The correlation coefficients for simultaneous occurrence of particle precipitation and PMSE intensity for time interval of various lengths $(t \geq 2.56 \mathrm{~min})$, all the combined data points having simultaneous occurrence of the two phenomena for $(t \geq 2.56 \mathrm{~min})$ in each hour, each day, and all the 5-day campaign have been estimated using the Pearson linear and Spearman rank correlation. On the basis of more robust Spearman rank correlation coefficient, the main results regarding a possible correlation between particle precipitation and PMSE intensity are summarized as follows:

- The percentages of events having positive and negative values of the correlation Spearman rank coefficients computed for simultaneously occurring PMSE and particle precipitation for time interval of various lengths ( $t \geq 2.56 \mathrm{~min})$ are 77.14 and $22.86 \%$, respectively.

- The percentages of events having positive and negative values of the Spearman rank correlation coefficients computed by combining all the data points 
having simultaneously occurring PMSE and particle precipitation for $(t \geq 2.56 \mathrm{~min})$ in each hour are 73.88 and $26.12 \%$, respectively.

- The Spearman rank correlation coefficient computed by combining all the data points having simultaneously occurring PMSE and particle precipitation for $(t \geq 2.56 \mathrm{~min})$ in each day also has dominant positive values.

- The Spearman rank correlation coefficient computed by combining all the data points having simultaneously occurring PMSE and particle precipitation in all the 5-day campaign also has positive value.

- During the simultaneous occurrence of PMSE and particle precipitation, the reason for both the positive and negative correlation coefficients might be the electron density variations due to the ionization caused by energetic particle precipitations. In particular, for the small percentage of negative correlation coefficients, it could be reasonable to suggest that during very strong precipitation, the ratio of aerosols charge to electron density becomes very small which weaken the strength of PMSE and hence cause a negative correlation.

\section{Abbreviations \\ PMSE: polar mesosphere summer echoes; EISCAT: European Incoherent Scat- ter; NLC: noctilucent clouds; MSPs: meteoric smoke particles; CNA: cosmic noise absorption; SNR: signal-to-noise ratio; PFISR: Poker Flat Incoherent Scatter Radar; NICT: National Institute of Information and Communications Technology.}

\section{Authors' contributions}

Manuscript preparation and data analysis was done by AR and HL. SU helps in plotting figures. LM, BW and MW give useful suggestions in discussing the results. All authors read and approved the final manuscript.

\section{Acknowledgements}

This work is supported by National Natural Science Foundation of China (Grant Nos. 41104097 and 41304119), Fundamental Research Funds for the Central Universities (ZYGX2015J039, ZYGX2015J037, and ZYGX2015J041). The EISCAT Scientific Association is supported by the research councils of China, Finland, France, Germany, Japan, Norway, Sweden, and UK.

\section{Competing interests}

The authors declare that they have no competing interests.

\section{Availability of data and materials}

Radar data is available through the EISCAT data portal: 08-12 July2013 data of manda experiment can be downloaded at: https://www.eiscat.se/schedule/ schedule.cgi?year $=2013 \&$ month $=7 \& S=0 n \& A=0 n \& V H F=0 n$.

\section{Consent for publication}

Not applicable.

\section{Ethics approval and consent to participate}

Not applicable.

\section{Funding}

This work is supported by National Natural Science Foundation of China (Grant Nos. 41104097 and 41304119), Fundamental Research Funds for the Central Universities (ZYGX2015J039, ZYGX2015J037, and ZYGX2015J041).

\section{Publisher's Note}

Springer Nature remains neutral with regard to jurisdictional claims in published maps and institutional affiliations.

Received: 20 February 2018 Accepted: 26 June 2018

Published online: 03 July 2018

\section{References}

Antonsen T, Havnes O (2015) On the relationship between PMSE strength and particle precipitation. Paper presented at the 22nd ESA Symposium on European Rocket and Balloon Programmes and Related Research, Tromsø, Norway, 7-12 June 2015. http://hdl.handle.net/10037/8607

Barabash V, Kirkwood S, Chilson PB (2002) Are variations in PMSE intensity affected by energetic particle precipitation? Ann Geophys 20: 539-54. http://www.ann-geophys.net/20/539/2002/

Barabash V, Kirkwood S, Feofilov A, Kutepov A (2004) Polar mesosphere summer echoes during the July 2000 solar proton event. Ann Geophys 22: 759-771. https://www.ann-geophys.net/22/759/2004/angeo-22-7592004.pdf

Baumann C, Rapp M, Anttila M, Kero A, Verronen PT (2015) Effects of meteoric smoke particles on the D region ion chemistry. J Geophys Res 120:10823-10839. https://doi.org/10.1002/2015JA021927

Bremer J, Singer W, Keuer D, Hoffmann P, Röttger J, Cho JYN, Swartz WE (1995) Observations of polar mesosphere summer echoes at EISCAT during summer 1991. Radio Sci 30:1219-1228. https://doi.org/10.1029/95RSO 0651

Bremer J, Hoffmann P, Hansen TL (2000) Geomagnetic control of polar mesosphere summer echoes. Ann Geophys 18:202-208. https://doi. org/10.1007/s00585-000-0202-z

Bremer J, Hansen TL, Hoffmann P, Latteck R (2001) Dependence of polar mesosphere summer echoes on solar wind and geomagnetic activity. Adv Space Res 28:1071-1076. https://doi.org/10.1016/S0273-1177(01)80039-9

Bremer J, Hoffmann P, Höffner J, Latteck R, Singer W, Zecha M, Zeller O (2006) Long-term changes of mesospheric summer echoes at polar and middle latitudes. J Atmos Sol Terr Phys 68:1940-1951. https://doi.org/10.1016/j. jastp.2006.02.012

Cho JYN, Röttger J (1997) An updated review of polar mesosphere summer echoes: observation, theory, and their relationship to noctilucent clouds and sub visible aerosols. J Geophys Res 102:2001-2020. https://doi. org/10.1029/96JD02030

Cho JYN, Hall TM, Kelly MC (1992) On the role of charged aerosols in polar mesosphere summer echoes. J Geophys Res 97(D1):875-886. https://doi. org/10.1029/91JD02836

Czechowsky P, Reid IM, Rüster R, Schmidt G (1989) VHF radar echoes observed in the summer and winter polar mesosphere over Andøya, Norway. J Geophys Res 94:5199-5217. https://doi.org/10.1029/JD094iD04p05199

Ecklund WL, Balsley BB (1981) Long-term observations of the Arctic mesosphere with the MST radar at Poker Flat, Alaska. J Geophys Res 86:7775-7780. https://doi.org/10.1029/JA086iA09p07775

Evans JD (1996) Straight forward statistics for the behavioral sciences. Brooks/ Cole Pub. Co, Pacific Grove

Friedrich M, Torkar KM (1983) High-latitude plasma densities and their relation to riometer absorption. J Atmos Terr Phys 45:127-135. https://doi. org/10.1016/S0021-9169(83)80017-8

Friedrich M, Harrich M, Torkar KM, Kirkwood S (2004) The disturbed auroral ionosphere based on EISCAT and rocket data. Adv Space Res 33:949-955. https://doi.org/10.1016/j.asr.2003.08.007

Havnes O, Gumbel J, AntonsenT Hedin J, La Hoz C (2014) On the size distribution of collision fragments of NLC dust particles and their relevance to meteoric smoke particles. J Atmos Sol Terr Phys 118:190-198. https://doi. org/10.1016/j.jastp.2014.03.008

Hervig ME, Thompson RE, McHugh M, Gordley LL, Russell JM, Summers ME (2001) First confirmation that water ice is the primary component of polar mesospheric clouds. Geophys Res Lett 28:971-974

Hervig ME, Deaver LE, Bardeen CG, Russell JM, Bailey SM, Gordley LL (2012) The content and composition of meteoric smoke in mesospheric ice particles from SOFIE observations. J Atmos Sol Terr Phys 84-85:1-6. https://doi. org/10.1016/j.jastp.2012.04.005 
Hocking WK, Röttger J (1997) Studies of polar mesosphere summer echoes over EISCAT using calibrated signal strengths and statistical parameters. Radio Sci 32:1425-1444. https://doi.org/10.1029/97RS00716

Hoffmann P, Singer W, Bremer J (1999) Mean seasonal and diurnal variations of PMSE and winds from 4 years of radar observations at ALOMAR. Geophys Res Lett 26:1525-1528. https://doi.org/10.1029/1999GL900279

Jackman CH, Roble RG, Fleming EL (2007) Mesospheric dynamical changes induced by the solar proton events in October-November 2003. Geophys Res Lett 34:L04812. https://doi.org/10.1029/2006GL028328

Kelley MC, Farley DT, Röttger J (1987) The effect of cluster ions on anomalous VHF backscatter from the summer polar mesosphere. Geophys Res Lett 14:1031-1034. https://doi.org/10.1029/GL014i010p01031

Klostermeyer J (1999) On the diurnal variation of polar mesosphere summer echoes. Geophys Res Lett 26:3301-3304. https://doi.org/10.1029/1999G L003629

Li Q, Rapp M (2011) PMSE-observations with the EISCAT VHF and UHF-radars: statistical properties. J Atmos Sol Terr Phys 73:944-956

Lübken F-J, Höffner J (2004) Experimental evidence for ice particle interaction with metal atoms at the high latitude summer mesopause region. Geophys Res Lett 31:L08103. https://doi.org/10.1029/2004GL019586

Megner L, Gumbel J (2009) Charged meteoric particles as ice nuclei in the mesosphere: part 2. A feasibility study. J Atmos Sol Terr Phys 71:12361244. https://doi.org/10.1016/j.jastp.2009.05.002

Morris RJ, Terkildsen MB, Holdsworth AD, Hyde MR (2005) Is there a causal relationship between cosmic noise absorption and PMSE? Geophys Res Lett 32:L24809. https://doi.org/10.1029/2005GL024568

Plane JMC (2004) A time-resolved model of the mesospheric Na layer: constraints on the meteor input function. Atmos Chem Phys 4:627-638

Plane JMC, Feng W, Dawkins ECM (2015) The mesosphere and metals: chemistry and changes. Chem Rev 115:4497-4541

Rapp M, Lübken F-J (2004) Polar mesosphere summer echoes (PMSE): review of observations and current understanding. Atmos Chem Phys 4: 2601-2633. http://www.atmos-chem-phys.net/4/2601/2004/

Rapp M, Gumbel J, Lübken F-J, Latteck R (2002) D region electron number density limits for the existence of polar mesosphere summer echoes. J Geophys Res 107:ACH 2-1-ACH 2-13. https://doi.org/10.1029/2001 J D001323

Rishbeth H, van Eyken AP, Lanchester BS, Turunen T, Röttger J, Hall C, Hoppe U-P (1988) EISCAT VHF radar observations of periodic mesopause echoes. Planet Space Sci 36:423-428. https://doi.org/10.1016/00320633(88)90131-6

Roble RG, Emery BA, Killeen TL, Reid GC, Solomon S, Garcia RR, Evans DS, Hays PB, Carignan GR, Heelis RA, Hanson WB, Winningham DJ, Spencer NW, Brace LH (1987) Joule heating in the mesosphere and thermosphere during the July 13, 1982. Sol Proton Event J Geophys Res 92:6083-6090. https://doi.org/10.1029/JA092iA06p06083
Röttger J, Rietveld MT, La Hoz C, Hall T, Kelley MC, Swartz WE (1990) Polar mesosphere summer echoes observed with the EISCAT $933 \mathrm{MHz}$ radar and the CUPRI $46.9 \mathrm{MHz}$ radar, their similarity to $224 \mathrm{MHz}$ radar echoes, and their relation to turbulence and electron density profiles. Radio Sci 25:671-687. https://doi.org/10.1029/RS025i004p00671

She CY, Williams BP, Hoffmann P, Latteck R, Baumgarten G, Vance JD, Fiedler J, Acott P, Fritts DC, Lübken F-J (2006) Simultaneous observation of sodium atoms, NLC and PMSE in the summer mesopause region above ALOMAR, Norway $\left(69^{\circ} \mathrm{N}, 12^{\circ} \mathrm{E}\right)$. J Atmos Sol Terr Phys 68:93-101. https:// doi.org/10.1016/j.jastp.2005.08.014

Singer W, Latteck R, Hoffmann P, Williams BP, Fritts DC, Murayama Y, Sakanoi K (2005) Tides near the Arctic summer mesopause during the MaCWAVE/ MIDAS summer program. Geophys Res Lett 32:L07S90. https://doi. org/10.1029/2004GL021607

Singer W, Hoffmann P, Latteck R, Batista P (2008) Response of mesospheric temperatures and winds on solar proton events after meteor/MF radar observations. Paper presented at the 37th COSPAR Scientific Assembly, Montreal, Canada, 13-20 July 2008. 2008cosp...37.2910S

Smirnova M, Belova E, Kirkwood S, Mitchell N (2010) Polar mesosphere summer echoes with ESRAD, Kiruna, Sweden: variations and trends over 1997-2008. J Atmos Sol Terr Phys 72:435-447. https://doi.org/10.1016/j. jastp.2009.12.014

Varney RH, Nicolls MJ, Heinselman CJ, Kelley MC (2009) Observations of polar mesospheric summer echoes using PFISR during the summer of 2007. J Atmos Sol Terr Phys 71:470-476. https://doi.org/10.1016/j.jastp 2009.01.002

Von Savigny C, Sinnhuber M, Bovensmann H, Burrows JP, Kallenrode M-B, Schwartz M (2007) On the disappearance of noctilucent clouds during the January 2005 solar proton events. Geophys Res Lett 34:L20805. https ://doi.org/10.1029/2006GL028106

Von Zahn U, Bremer J (1999) Simultaneous and common-volume observations of noctilucent clouds and polar mesosphere summer echoes. Geophys Res Lett 26:1521-1524. https://doi.org/10.1029/1999GL900206

Wilks DS (1995) Statistical methods in the atmospheric sciences. Academic Press, San Diego

Zeller O, Bremer J (2009) The influence of geomagnetic activity on mesospheric summer echoes in middle and polar latitudes. Ann Geophys 27: 831-837. www.ann-geophys.net/27/831/2009/

\section{Submit your manuscript to a SpringerOpen ${ }^{\circ}$ journal and benefit from:}

- Convenient online submission

- Rigorous peer review

- Open access: articles freely available online

- High visibility within the field

Retaining the copyright to your article

Submit your next manuscript at springeropen.com 